\title{
ON THE STABILITY OF AN ALTERNATIVE QUADRATIC FUNCTIONAL EQUATION
}

\section{PAISAN NAKMAHACHALASINT}

Abstract. We will investigate the stability of the alternative quadratic functional equation

$$
f(x+y)+f(x-y)+2 f(x)+2 f(y) \neq 0 \Rightarrow f(x+y)+f(x-y)=2 f(x)+2 f(y) .
$$

Mathematics subject classification (2010): 39B52, 39B82.

Keywords and phrases: Alternative functional equation; Quadratic functional equation; Stability of functional equation.

\section{REFERENCES}

[1] B. BAтKo, On the stability of an alternative functional equation, Math. Inequal. Appl. 8 (2005), 685691

[2] B. BATKo AND J. TABOR, Stability of an alternative Cauchy equation on a restricted domain, Aequationes Math. 57 (1999), 221-232.

[3] B. Batko And J. TABor, Stability of the generalized alternative Cauchy equation, Abh. Math. Sem. Univ. Hamb. 69 (1999), 67-73.

[4] S. CzERWIK, Functional Equations and Inequalities in Several Variables, World Scientific, Singapore, 2002

[5] D. H. Hyers, On the Stability of the Linear Functional Equations, Proc. Natl. Acad. Sci. 27 (1941), 222-224.

[6] J. M. Rassias, On the General Quadratic Functional Equation, Bol. Soc. Mat. Mexicana 11 (2005), 259-268.

[7] TH. M. Rassias, On the Stability of the Linear Mapping in Banach Spaces, Proc. Amer. Math. Soc. 72 (1978), 297-300.

[8] S. M. Ulam, Problems in Modern Mathematics, Wiley-Interscience, New York, 1964. 